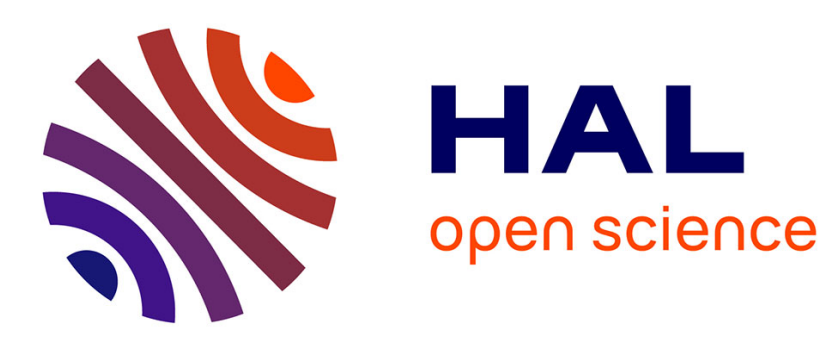

\title{
Distance Perception During Cooperative Virtual Locomotion
}

William Eric Marsh, Jean-Rémy Chardonnet, Frédéric Merienne

\section{To cite this version:}

William Eric Marsh, Jean-Rémy Chardonnet, Frédéric Merienne. Distance Perception During Cooperative Virtual Locomotion. IEEE Symposium on 3D User Interfaces, Mar 2015, Arles, France. pp.173-174. hal-01138790

\section{HAL Id: hal-01138790 \\ https://hal.science/hal-01138790}

Submitted on 2 Apr 2015

HAL is a multi-disciplinary open access archive for the deposit and dissemination of scientific research documents, whether they are published or not. The documents may come from teaching and research institutions in France or abroad, or from public or private research centers.
L'archive ouverte pluridisciplinaire HAL, est destinée au dépôt et à la diffusion de documents scientifiques de niveau recherche, publiés ou non, émanant des établissements d'enseignement et de recherche français ou étrangers, des laboratoires publics ou privés. 


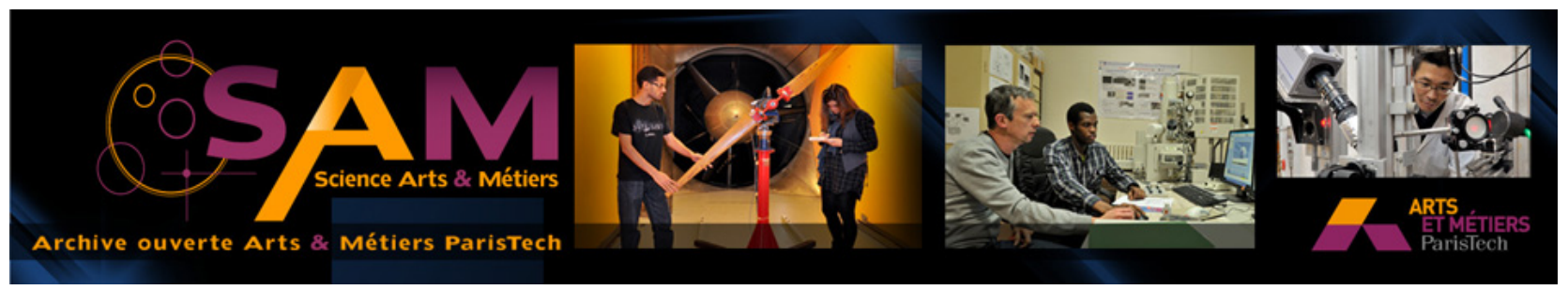

Science Arts \& Métiers (SAM)

is an open access repository that collects the work of Arts et Métiers ParisTech researchers and makes it freely available over the web where possible.

This is an author-deposited version published in: http://sam.ensam.eu

Handle ID: .http://hdl.handle.net/10985/9435

\section{To cite this version :}

William Eric MARSH, Jean-Rémy CHARDONNET, Frédéric MERIENNE - Distance Perception During Cooperative Virtual Locomotion - In: IEEE Symposium on 3D User Interfaces, France, 2015-03-22 - IEEE Symposium on 3D User Interfaces (poster session) - 2015 


\title{
Distance Perception During Cooperative Virtual Locomotion
}

\author{
William E. Marsh* Jean-Rémy Chardonnet ${ }^{\dagger} \quad$ Frédéric Mérienne
}

Arts et Métiers ParisTech — CNRS Le2i, Institut Image

\begin{abstract}
Virtual distances are often misperceived, though most past research ignores co-located cooperative systems. Because active locomotion plays a role in spatial perception, cooperative viewpoint control may impact perceived distances. Additionally, the center of projection is generally optimized for a single tracked user, meaning that a single action will result in different visual feedback for each user. We describe a study investigating the effect of a co-located cooperative locomotion interface on virtual distance perception. Results indicate that a slight center-of-projection offset did affect distance estimates for the untracked user, but that the cooperation actions themselves did not play a role. This study brings new insights to designing interfaces which facilitate accurate spatial perception in cooperative applications.
\end{abstract}

Index Terms: H.5.1 [Information Interfaces and Presentation]: Multimedia Information Systems-Artificial, augmented, and virtual realities; H.5.2 [Information Interfaces and Presentation]: User Interfaces-Input devices and strategies; H.5.3 [Information Interfaces and Presentation]: Group and Organization Interfaces Computer-supported cooperative work

\section{INTRODUCTION}

Virtual reality (VR) is utilized by decision makers in many domains where spatial perception is important. Virtual architecture, for example, is unique in that scenes are often viewed collaboratively in a system comprising one or more large screens, as opposed to using a head mounted display. However, challenges arise due to distance perception biases, which are well documented in VR but not completely understood.

Many visual cues are available in the physical world, but most relevant here are those relating to self-motion, such as motion parallax and optic flow. The act of moving also generates body-based feedback [5] which is integrated with visual cues. The capacity and intention to interact with the environment [6] have also been shown to impact perceived distances.

Virtual distance spans are often underestimated by up to about $50 \%$ [2], likely due to a combination of sensory discrepancies, equipment constraints, and unnatural interfaces. Most past researchers have used head mounted displays, but Marsh et al. [3] investigated the use of physical cues in addition to virtual cues when using a CAVE. In the present paper we investigate the effect of cooperative control of virtual locomotion on distance estimates. Additionally, CAVE graphics are usually optimized for a single tracked viewpoint. Pollock et al. [4] showed that viewing from a different location affects perception, but not to the extent predicted by geometry alone.

\footnotetext{
*e-mail: william@wemarsh.com

†e-mail:jean-remy.chardonnet@ensam.eu

†e-mail:frederic.merienne@ensam.eu
}

\section{EXPERIMENT}

\subsection{Design and Hypothesis}

We compared distance estimates when one user controls virtual travel versus when users travel cooperatively. Input was manipulated by allowing each user to judge distances after traversing them using the interface in each of two cooperation conditions: solo and paired. Feedback was manipulated during the paired condition such that each user experienced two tracking conditions: tracked and untracked. In the untracked condition, graphics were optimized for the viewing position of the participant's partner. Perceived distances were assessed using a timed imagined walking paradigm [1] with percent error as the dependent variable.

We predicted that distance estimates would be shorter in the paired condition, due to the importance of active control of movement and the observation that our collaborative interface involves approximately $50 \%$ passive translation. We predicted that tracking should not impact the distance estimates, as participants stood relatively close together and all movements were simple uni-directional translations. The amount of optic flow should be the same from either viewpoint, and much information regarding distance traveled can be obtained from watching the floor textures. Because the virtual floor is coplanar with the physical CAVE floor, an incorrect center of projection does not affect floor graphics.

Depth judgements could be biased if the untracked participant was a different height than the tracked participant. For example, if the tracked user is shorter than the untracked user, the untracked user should perceive a distant target to be at a greater angular declination than he should if he were the tracked user. The inverse is also true however, meaning that this effect should cancel out.

\subsection{Participants}

Eight male volunteers ranging from 22 to 25 years of age participated. All were familiar with VR, but none had experience in the experimental scene.

\subsection{Apparatus and Stimuli}

Virtual trials were conducted in a four-sided CAVE. The projection area on each wall was $3.0 \mathrm{~m}$ high $\times 2.67 \mathrm{~m}$ wide. One participant's head position was tracked using a four-camera Advanced Realtime Tracking system. The experimental scene was a virtual mosque with distance spans marked using virtual cone models on the floor.

A Logitech F710 Wireless Gamepad was used for locomotion. Each analog stick produced a virtual "step" forward. It was necessary to alternate between left and right steps, using the left and right sticks, respectively. For the paired condition, both participants held a single gamepad such that each controlled a stick. Imagined walking time was measured using two stopwatches (one for each participant). They were modified so they did not beep and white noise was played during the paired sessions to mask the "click."

\subsection{Procedures}

The interpupillary distance (IPD) for each volunteer was measured. They were then paired to minimize the IPD difference within pairs, and then each pair was assigned an IPD which was the average of the two participants' measurements. The maximum difference between a participant's IPD and the pair IPD was $1.25 \mathrm{~mm}$. 


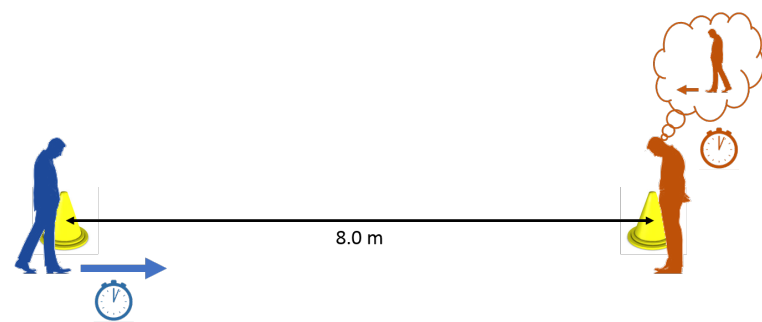

Figure 1: In the physical solo trials, participants timed themselves walking to the second cone, then again while imagining returning to the first cone.

Table 1: Cell means and marginal means for percent error. Positive numbers reflect overestimation.

\begin{tabular}{l|cc|c} 
& paired & solo & \\
\hline tracked & $66.1 \%$ & $69.0 \%$ & $68.0 \%$ \\
untracked & $89.3 \%$ & - & $89.3 \%$ \\
\hline & $77.7 \%$ & $69.0 \%$ &
\end{tabular}

There were two sessions (in order): solo and paired.

In the solo session, each participant walked an $8.00 \mathrm{~m}$ physical distance span (both directions), marked by a pair of yellow cones as seen in Figure 1. Walking started from beside the first cone and ended directly beside the second cone. The participant pressed the button to start the stopwatch when walking commenced and to stop it upon reaching the second cone. After each traversal, the participant closed his eyes, turned $180^{\circ}$, and imagined walking to the first cone. He started the stopwatch when imagined walking commenced and stopped it when he believed that the second cone had been reached. The times were averaged to arrive at individual physical and imagined speeds.

Next the participant completed six virtual trials in which he stood slightly to the right of CAVE-center. When each trial started, he was placed in the virtual mosque scene with the first virtual cone to the left of his feet. The second virtual cone was randomly placed $6.00 \mathrm{~m}, 8.00 \mathrm{~m}$, or $10.00 \mathrm{~m}$ from the first, such that each span was experienced two times. The participant was asked to use the gamepad to traverse the span. After each trial, the participant closed his eyes, physically turned $180^{\circ}$, and imagined walking to the starting position. As before, the participant used the stopwatch to time the imagined walk.

In the paired session, pairs completed six trials. Participants stood on each side of of CAVE-center. The trials proceeded like those in the solo sessions except the gamepad walking interface was used cooperatively, with each participant controlling one stick. Participants alternated wearing the tracked glasses.

\section{Results}

A paired t-test showed no significant difference between real and imagined walking times in the physical world, $t(7)=0.26, p=.81$. We therefore used each participant's real walking speed $(M=$ $1.06 \mathrm{~m} / \mathrm{s}$ ) as the basis for calculating the imagined virtual distances, which were then used to compute the percent error for each trial. On average, spans were overestimated by $73.4 \%$.

Because participants were tracked during all trials in the solo sessions, two separate ANOVAs were conducted. Cell means and marginal means for percent error are shown in Table 1.

A linear mixed model was created with percent error as a response, with cooperation, distance, and their interaction as fixed effects, and with a random intercept for pairs and for participants nested within pairs. A type-3 ANOVA was conducted using the Satterthwaite approximation for degrees of freedom. This showed that cooperation was not significant, $F(1,82.98)=1.01, p=.32$.
A linear mixed model was created with percent error as a response, with tracking, distance, and their interaction as fixed effects, and with a random intercept for pairs and for participants nested within pairs. Trials from both the solo and paired sessions were included in this model. A type-3 ANOVA was conducted using the Satterthwaite approximation for degrees of freedom, revealing a significant main effect of tracking, $F(1,82.98)=4.57, p=$ .04 .

\section{Conclusion}

We found no effect of cooperation on distance estimates, contrary to our predictions. This is surprising because the paired condition involved less control of self-motion than the solo condition. Note, however, that we cannot draw firm conclusions because the absence of statistical significance does not imply equivalence. We still believe these findings are interesting because the means were quite close together for practical purposes. The cooperative gamepad locomotion interface was highly unnatural, even in the solo condition. In the paired condition, participants needed to work together primarily to converge on a speed of manipulation. If the participants were out of sync, some actions would have no effect. Future work should consider interfaces that require more difficult cooperative actions and produce more complex feedback.

The slight difference in head position between the tracked participant and the untracked participant significantly impacted distance judgements. This is surprising because much of the movement feedback was on the floor, which was rendered correctly for both users. Under our conditions, users may have tended to assess the scene visually, possibly before movement began, instead of relying on movement feedback. These visual judgements may have been biased by an incorrect center of projection. Future work should determine if this is still true when a body-based interface is used.

Finally, future work should include more diverse participants. Results may be different among females, who often have different spatial abilities than males, or among users from the general public, who may be less comfortable using VR technology. Perhaps findings may be different for partners with very mismatched interface abilities, attempting to work together.

\section{ACKNOWLEDGEMENTS}

This work was supported by FUI Callisto.

\section{REFERENCES}

[1] E. Klein, J. E. Swan II, G. S. Schmidt, M. A. Livingston, and O. G. Staadt. Measurement protocols for medium-field distance perception in large-screen immersive displays. In Proceedings of IEEE Virtual Reality (IEEE VR 2009), pages 107-113, Los Alamitos, CA, 2009. IEEE Computer Society.

[2] J. M. Loomis and J. M. Knapp. Visual perception of egocentric distance in real and virtual environments. In L. J. Hettinger and M. W. Haas, editors, Virtual and Adaptive Environments: Applications, Implications, and Human Performance Issues, pages 21-46. CRC Press, Mahwah, NJ, 2003.

[3] W. E. Marsh, J.-R. Chardonnet, and F. Merienne. Virtual distance estimation in a CAVE. In C. Freksa, B. Nebel, M. Hegarty, and T. Barkowsky, editors, Spatial Cognition IX, Lecture Notes in Artificial Intelligence 8684, pages 354-369, Switzerland, 2014. Springer.

[4] B. Pollock, M. Burton, J. W. Kelly, S. Gilbert, and E. Winer. The right view from the wrong location: Depth perception in stereoscopic multi-user virtual environments. IEEE Transactions on Visualization and Computer Graphics, 18(4):581-588, 2012.

[5] D. Waller, J. M. Loomis, and D. B. M. Haun. Body-based senses enhance knowledge of directions in large-scale environments. Psychonomic Bulletin \& Review, 11(1):157-163, 2004.

[6] J. K. Witt, D. R. Proffitt, and W. Epstein. Perceiving distance: A role of effort and intent. Perception, 33:577-590, 2004. 